\title{
The impact of preoperative anxiety and education level on long-term mortality after cardiac surgery
}

Zsuzsanna Cserép ${ }^{1}$, Eszter Losoncz², Piroska Balog³, Tamás Szili-Török ${ }^{4}$ András Husz , Boglárka Juhász ${ }^{4}$, Miklós D Kertai ${ }^{1}$, János Gál ${ }^{1}$ and Andrea Székely ${ }^{1,5^{*}}$

\begin{abstract}
Background: Psychosocial factors have shown independent predictive value in the development of cardiovascular diseases. Although there is strong evidence to support the role of psychosocial factors in cardiovascular mortality, there is a scarcity of knowledge about how these factors are related. Therefore, we investigated the relationship between depression, anxiety, education, social isolation and mortality 7.5 years after cardiac surgery.

Methods: After informed consent, 180 patients undergoing cardiac surgery between July 2000 and May 2001 were prospectively enrolled and followed for ten years. During the follow-up period, the patients were contacted annually by mail. Anxiety (Spielberger State-Trait Anxiety Inventory, STAI-S/STAI-T), depression (Beck Depression Inventory, BDI) and the number and reason for rehospitalizations were assessed each year. Those patients who did not respond were contacted by telephone, and national registries were searched for deaths.

Results: During a median follow-up of 7.6 years $\left(25^{\text {th }}\right.$ to $75^{\text {th }}$ percentile, 7.4 to 8.1 years), the mortality rate was 23.6\% (95\% confidence interval [CI] 17.3-29.9; 42 deaths). In a Cox regression model, the risk factors associated with an increased risk of mortality were a higher EUROSCORE (points; Adjusted Hazard Ratio (AHR):1.30, 95\%Cl:1.07-1.58)), a higher preoperative STAI-T score (points; AHR:1.06, 95\%Cl 1.02-1.09), lower education level (school years; AHR:0.86, 95\%Cl:0.74-0.98), and the occurrence of major adverse cardiac and cerebral events during follow up (AHR:7.24, 95\% Cl:2.65-19.7). In the postdischarge model, the same risk factors remained.
\end{abstract}

Conclusions: Our results suggest that the assessment of psychosocial factors, particularly anxiety and education may help identify patients at an increased risk for long-term mortality after cardiac surgery.

Keywords: Mortality, Cardiac surgery, Anxiety, Depression, Education

\section{Background}

Psychosocial factors such as anxiety, depression, negative affectivity, and social inhibition are measurements that can potentially relate psychological phenomena to the social environment and to pathophysiological changes [1]. Symptoms of anxiety and depression are common psychological disturbances among patients with coronary artery disease, including those undergoing coronary artery bypass graft (CABG) surgery [2], which is an

\footnotetext{
*Correspondence: szekelya@kardio.hu

'Department of Anesthesiology and Intensive Care, Semmelweis University, Budapest $\mathrm{H}-1085$, Hungary

${ }^{5}$ Department of Anesthesia and Intensive Care, Gottsegen György Hungarian Institute of Cardiology, Haller u. 29, Budapest H-1096, Hungary

Full list of author information is available at the end of the article
}

effective therapy for prolonging life and decreasing symptoms in appropriately selected patients [3]. Previously, we showed that patients with high preoperative anxiety have a significantly higher mortality rate four years after surgery [4]. Socially isolated people (e.g., those who are single or have a small social network) have a higher risk for morbidity and mortality according to recent studies [5]. Myocardial infarction-related morbidity and mortality increase with the severity of depressive and anxiety symptoms, especially in patients with a low education status and social support. In the INTERHEART study, low education status markedly increased the incidence of myocardial infarction after adjusting for

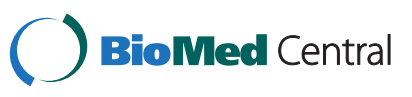


age, gender, ethnicity, blood cholesterol, hypertension, diabetes and smoking [6].

The aim of the current study was to define the incidence and the time-course of preoperative and postdischarge depression and anxiety in patients underwent cardiac surgery. Furthermore we aimed to examine the association between depression, anxiety scores and mortality 7.5 years after discharge from hospital.

\section{Methods}

\section{Study population}

The study population comprised 197 consecutive patients admitted for elective CABG or valve surgery at the Gottsegen Hungarian Institute of Cardiology between July 2000 and May 2001. There was no eligibility restriction in terms of age, gender, or cardiac condition and no classification of on- and off-pump procedures. After admission to the surgical ward, a study nurse invited the patients to participate in the study. All patients signed an informed consent. The baseline questionnaires were completed 1-5 days before surgery. Seventeen patients (8.6\%) were excluded because of a cancelled surgery $(N=9)$ or an inability to complete the psychological tests $(N=8)$. Thus, a total of 180 patients were prospectively studied. The patients who were alive at the end of the 7.5-year follow-up period were considered the survival group, and the patients who died during the follow-up period were considered the nonsurvival group. The study was approved by the Institutional Medical Ethics Committee. The authors had full access to the data and took responsibility for its integrity. Our previous findings on the fourth year of follow up are reported elsewhere [4].

\section{Clinical factors}

A range of medical and psychosocial factors were assessed as potential determinants of outcome. Medical factors included previous myocardial infarction, previous CABG, history of arrhythmia, congestive heart failure (CHF) (defined as paroxysmal nocturnal dyspnea, dyspnea on exertion, pulmonary congestion on chest $\mathrm{x}$-ray, pedal edema or dyspnea and receiving diuretics or digoxin within the last 2 weeks), diabetes mellitus, hypercholesterolemia, cerebrovascular disease, chronic renal insufficiency, hypertension, and history of psychiatric treatment. Detailed definitions can be accessed on the homepage of the Society of Thoracic Surgeons (STS National Database). The additive EUROSCORE was calculated on the basis of preoperative risk factors to assess and predict the chances of cure and fatal outcome in patients with coronary and heart valve operations [7]. Intraoperative characteristics included the number of grafted vessels, cardiopulmonary bypass $(\mathrm{CPB})$ time, and aortic cross-clamp time. Postoperative complications were defined by the key outcomes of the Society of Thoracic Surgeons Database [8]. After discharge, the occurrence of MACCE (major adverse cardiac and cerebral event) was used to characterize the postdischarge condition of the patient. A MACCE was defined as any of the following: angina; CHF; myocardial infarction; percutaneous coronary angioplasty; survived cardiac arrest; or death due to cardiac causes, stroke, re-CABG, or valve replacement.

\section{Psychosocial factors}

Demographic data on age, gender, living status (alone vs. together with someone), and education (number of successfully finished school years) were collected. Depression was assessed using the Beck Depression Inventory (BDI), a questionnaire previously used with cardiac patients [9]. The BDI is a 21-item self-report instrument measuring the clinical manifestations of depressive symptoms that correspond to the DSM-IV criteria [10]. Cronbach's alpha in this population was 0.88 . Cronbach's alpha is a coefficient of reliability and is commonly used as a measure of the internal consistency or reliability of a psychometric test score. The alpha coefficient ranges in value from 0 to 1 and may be used to describe the reliability of factors extracted from dichotomous and/or multi-point formatted questionnaires or scales (i.e., rating scale: 1 = poor, $5=$ excellent). The higher the score is, the more reliable the generated scale [11].

The Spielberger State-Trait Anxiety Inventory state and trait scores (STAI-S and STAI-T) were used to characterize the patients' anxiety symptoms. The STAI-S measures the transitional emotional status evoked by a stressful situation, such as surgery. The STAI-T score reflects relatively enduring individual differences in the likelihood of anxiety [12]. Cronbach's alpha in this population was 0.94 .

Education was measured by school years and categorized into three groups: less than 8 years of education, more than 12 years of education and more than 8 but less than 12 years. In Hungary, compulsory schooling is finished at the end of the eighth year of school and the upper-secondary education at the end of the twelfth year of school. Education years were calculated as successfully finished school years (i.e., if somebody needed to reattempt the fifth grade, he or she was graded as a fifth grade graduate despite 6 total years of school).

\section{Follow-up surveillance}

The BDI, STAI-S, and STAI-T tests were sent to the patients along with an additional sheet of questions regarding hospitalization and the primary cause of their hospital admission since the last communication. The patients were contacted by mail $6,12,24,36,48,60$ and 82 months after discharge. For those patients who did 
not respond and their proxy was unavailable for contact, the Hungarian registry was searched for mortality information at the end of the seventh year.

\section{End-point assessment}

Our end point was all-cause mortality. In $70 \%$ of the cases, the clinical data were retrieved from the registry of our hospital where the patients were treated. In the remaining $30 \%$, the data were retrieved from the family doctors' registry. Therefore, the mortality and date of death were available for each patient in the study population.

\section{Statistical analysis}

The data are described as the mean and standard deviation (SD) or the median and interquartile range (25th to 75 th percentile) for continuous variables and as the number and percent for categorical variables. The median (25th to 75th percentile) follow-up was computed according to the Kaplan-Meier method. The observation time extended from the date of discharge to the date of death or censoring. Preoperative and operative patient characteristics were compared according to the occurrence of postoperative mortality by means of the Student $t$ test or the Mann-Whitney $U$ test and the Fisher exact test for continuous and categorical variables, respectively. Paired t-test and Pearson correlation were used for analyzing the pre- and post-discharge BDI and STAI-T points.

The cumulative survival probability and $95 \%$ confidence intervals (CIs) were computed and plotted separately for survival and death according to the KaplanMeier method. The prognostic value of perioperative and psychosocial factors was evaluated by means of Cox regression. We used Cox proportional-hazards analysis to identify factors associated with mortality after cardiac surgery. Candidate variables were included in the initial Cox regression model if they were associated with mortality in a univariate analysis $(\mathrm{P}<0.20)$. The final multivariable Cox proportional hazards regression model was then derived according to the backward deletion of the least-significant predictors. This statistical model is a type of survival model in which predetermined covariates or risk factors, such as patient characteristics and co-morbidities, are assessed for their independent association with the hazard of mortality. Hazard ratios and the corresponding 95\% CIs are reported. Furthermore, we quantified the discriminatory power of the final multivariable model using the c-index, which corresponds to the area under the receiver operating characteristic curve, ranging from 0.5 (performance at chance) to 1.0 (perfect performance). To evaluate the discriminatory power of the final multivariable model, a bootstrap method was used to assess the degree of over-optimism.
Over-optimism occurs when the application of statistical modeling techniques results in models that inaccurately predict outcomes for subsequent datasets. A bootstrapping procedure is one method that can be used to try to correct for this over-optimism [13]. The covariates in the final model were fitted for each bootstrap sample. The original dataset was fitted using the coefficients of the bootstrap sample model, and thus, a c-index statistic was generated from this fit on the original dataset. Optimism was then estimated as the difference between the c-index from the bootstrap sample and from the bootstrap model fit on the original sample. All tests were 2 sided, and a value of $\mathrm{P}<0.05$ was considered to be statistically significant. These analyses were performed using SPSS statistical software (PASW Statistics 18.0; SPSS Inc., Chicago, IL).

In the post-discharge model, only patients who were discharged from the hospital and who had at least one BDI and STAI-T score during the follow up $(n=158)$ were analyzed.

\section{Results}

During a median follow-up of 7.6 years $\left(25^{\text {th }}\right.$ to $75^{\text {th }}$ percentile, 7.4 to 8.1 years), the mortality rate was $23.6 \%$ (95\% confidence interval [CI] 17.3-29.9; 42 deaths). Seven patients had in-hospital deaths. Despite the relatively long follow up period, 15 patients did not respond ("were lost to follow-up") to our questionnaires. Therefore, the analysis of postoperative anxiety and depression levels had a smaller sample size. The non-responder patients were more likely to spend more than two days in the intensive care unit (ICU), and they more frequently had a history of diabetes mellitus compared to those who responded to our follow-up mail questionnaires.

Patients who died on average were older, had a higher risk score (EUROSCORE), and were more frequently diabetic compared to patients who were alive at the end of the follow-up period. Patients who died had also higher preoperative BDI, STAI-S, and STAI-T and higher postdischarge BDI and STAI-T scores and a history of lower education level compared to patients who were alive at the end of the follow-up (Table 1).

During the follow-up period, the occurrence of a MACCE, malignant disease and rehospitalization were significantly higher in the non-survivor group (Table 1). Preoperative depression (BDI points) and anxiety (STAI $\mathrm{T}$ and $\mathrm{S}$ scores) were higher in patients who died during the follow-up period (Table 1). There were no significant changes in the mean pre- and postdischarge STAI-T $(-0.48$ vs. $-1.49 ; \mathrm{p}=0.37)$ and $\mathrm{BDI}(-0.83$ vs. -0.12 ; $\mathrm{p}=0.58$ ) between patients who died during follow-up and patient who were alive at the end of the follow-up, respectively. Pre- and postoperatively measured BDI $(\mathrm{r}=0.64 ; \mathrm{p}<0.001)$ and STAI-T $(\mathrm{r}=0.67 ; \mathrm{p}<0.001)$ 
Table 1 Perioperative characteristics of the study population

\begin{tabular}{|c|c|c|c|c|c|}
\hline \multicolumn{2}{|c|}{ Survivors $(N=138)$} & \multicolumn{2}{|c|}{ Deaths $(N=42)$} & \multirow[b]{2}{*}{$(\mathrm{SD}) / \%$} & \multirow[b]{2}{*}{$P$ value } \\
\hline & Mean/N & $(\mathrm{SD}) / \%$ & Mean/N & & \\
\hline \multicolumn{6}{|l|}{ Preoperative factors } \\
\hline Age (years) & 56.9 & $(10.5)$ & 60.9 & $(7.9)$ & 0.02 \\
\hline Diabetes & 28 & $20.3 \%$ & 11 & $26.2 \%$ & 0.04 \\
\hline Hypertension & 57 & $41.3 \%$ & 18 & $42.9 \%$ & 0.76 \\
\hline Hyperlipidaemia & 54 & $39.1 \%$ & 12 & $28.6 \%$ & 0.03 \\
\hline Peripheral vascular disease & 16 & $11.6 \%$ & 9 & $21.4 \%$ & 0.09 \\
\hline Arrhythmia & 29 & $21.0 \%$ & 9 & $21.4 \%$ & 0.89 \\
\hline Reoperation & 5 & $3.6 \%$ & 6 & $14.3 \%$ & 0.21 \\
\hline Psychiatric treatment & 14 & $10.1 \%$ & 12 & $28.6 \%$ & 0.003 \\
\hline Anxiolytics/ antidepressants & 61 & $44.2 \%$ & 12 & $28.6 \%$ & 0.02 \\
\hline \multicolumn{6}{|l|}{ Perioperative factors } \\
\hline CPB time (min) & 72.1 & $(47.7)$ & 88.2 & $(46.1)$ & 0.05 \\
\hline EUROSCORE (additive) & 3.1 & $(2.3)$ & 4.5 & $(2.6)$ & 0.002 \\
\hline ICU stay (days) & 1.4 & $(1.1)$ & 5.4 & $(11.6)$ & 0.001 \\
\hline Hospital stay (days) & 8.9 & (3.4) & 11.6 & $(13.8)$ & 0.04 \\
\hline \multicolumn{6}{|c|}{ Preoperative psychosocial factors } \\
\hline $\mathrm{BDI}$ & 8.7 & $(5.7)$ & 13.6 & $(9.8)$ & $<0.001$ \\
\hline STAI-S & 43.7 & $(10.8)$ & 48.5 & $(12.5)$ & 0.02 \\
\hline STAI-T & 42.7 & $(9.2)$ & 51.1 & $(9.8)$ & $<0.001$ \\
\hline School years & 11.4 & $(3.1)$ & 9.5 & (2.6) & $<0.001$ \\
\hline \multicolumn{6}{|l|}{ Postdischarge factors } \\
\hline MACCE & 42 & $30.4 \%$ & 36 & $85.7 \%$ & $<0.001$ \\
\hline Arrhythmia & 29 & $21.0 \%$ & 9 & $22.0 \%$ & 0.90 \\
\hline Malignancy & 0 & $0.0 \%$ & 4 & $9.5 \%$ & $<0.001$ \\
\hline Rehospitalization & 50 & $39.7 \%$ & 22 & $88.0 \%$ & $<0.001$ \\
\hline BDI (mean) & 7.8 & $(5.5)$ & 14.2 & $(10.1)$ & 0.004 \\
\hline STAI-T (mean) & 40.7 & $(9.2)$ & 48.5 & $(12.7)$ & 0.004 \\
\hline
\end{tabular}

N: number, SD: standard deviation, CPB time: cardiopulmonary bypass time, ICU: intensive care unit, BDI: Beck Depression Inventory, STAI-S: state anxiety subscale in the Spielberger State-Trait Anxiety Inventory, STAI-T: trait anxiety subscale in the Spielberger State-Trait Anxiety Inventory, MACCE: major adverse cardiac and cerebral event.

scores in the same patients showed a strong correlation (Figures 1 and 2). Patients who died had also a higher preoperative BDI, STAI-S, and STAI-T and higher postdischarge BDI and STAI-T scores: during the follow up the high level of depression and anxiety did not change. We did not find interaction between anxiolytics, psychiatric treatment, BDI and STAI-T values (data not shown).

At the end of follow-up, $64.7 \%$ (44 patients) in the low education group, $80.7 \%$ (63 patients) of the medium education group and $91.1 \%$ (31 patients) of the high education group were alive (Figure 3). Survival was influenced strongly by education. Those patients who had an academic degree had a mean survival time of 8.01 years (95\% CI: 7.37 to 8.65), patients with 9 to 12 years of education had a mean survival time of
7.73 years (95\% CI: 7.31 to 8.16 ) and the group with 8 years or less of education had a mean survival time of 7.03 years (95\% CI: 6.41 to 7.64). There were significant differences among patients with 8 years or less of education and patients with 8 to 12 years of education $(\mathrm{P}=0.032)$ and patients with an academic degree $(P=0.006)$ in the survival analysis. Patients with less education had a worse life expectancy. There was no significant difference between patients with 9 to 12 years of education and those with an academic degree $(\mathrm{P}=0.18)$.

In the perioperative and the postdischarge multivariable Cox models, the additive EUROSCORE, length of ICU stay, preoperative STAI-T points, school years and the occurrence of MACCE were independently associated with mortality (Table 2). In the interactive Cox regression model patients were categorized: anxious only, depression 


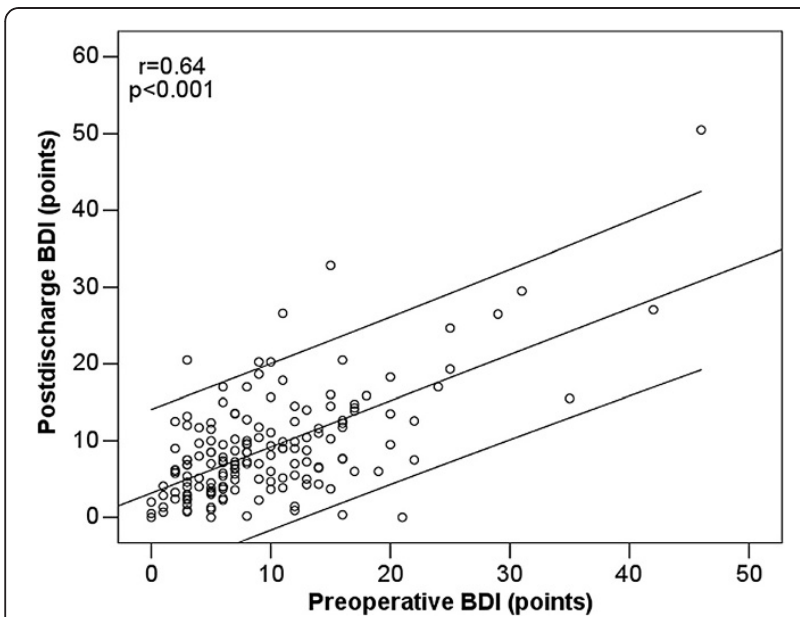

Figure 1 Figure shows the correlation between the mean of preoperative and postdischarge BDI points. The line shows correlation and $95 \% \mathrm{Cl}$.

only, neither, or both. In the study population, 54 ( $29.8 \%$ ) patients had no depression or anxiety, 48 (26.5\%) patients had only anxiety, (defined as STAI-T $\geq 40)$, 14 $(7.7 \%)$ patients had depression (defined as BDI $\geq 10$ ) and 65 (35.9\%) patients had both anxiety and depression. Compared the survivals and deaths patients with anxiety and anxiety and depression together had significantly higher risk for death (Table 3).

\section{Discussion}

We found that trait scores of anxiety (STAI-T), and education level were associated with a higher risk of mortality after adjusting for medical factors and postdischarge major cardiac events during 7.5 years of follow up after cardiac surgery.

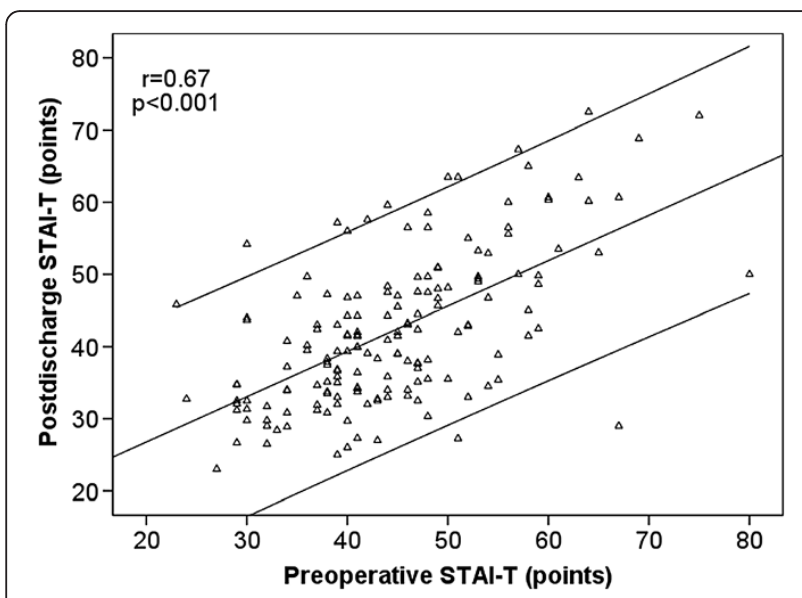

Figure 2 Figure shows the correlation between the mean of preoperative and postdischarge STAI-T points. The line shows correlation and $95 \% \mathrm{Cl}$.

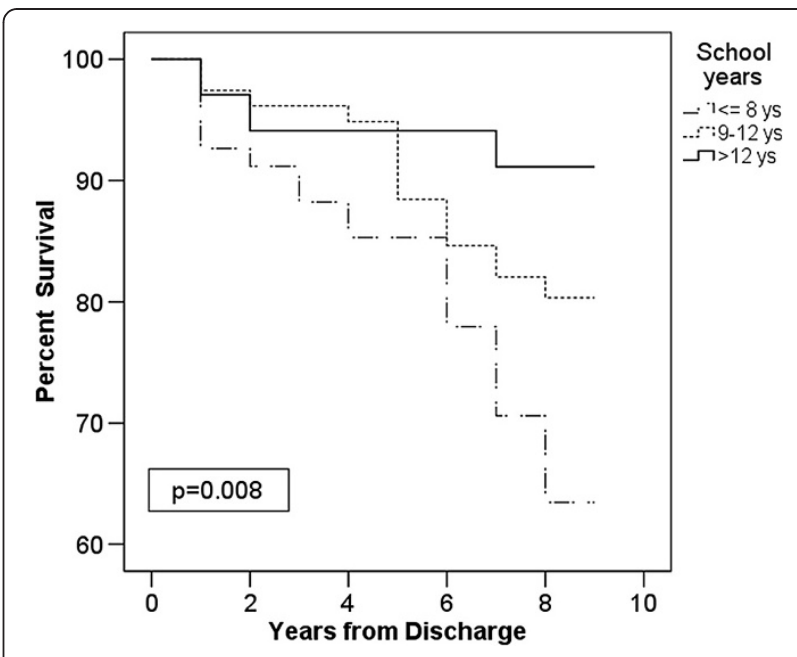

Figure 3 Kaplan-Meier analysis according to the level of education. Time after discharge is plotted against the percent survival.

Psychosocial risk factors, such as low socio-economic status, chronic family or work stress, social isolation, negative emotions (e.g., chronic depression or acute anxiety), and negative personality patterns, such as Type-Dpattern or hostility, have been shown to be significantly associated with the development of coronary artery disease and with the occurrence of adverse outcome in patients with established coronary artery disease [14].

Numerous studies have underlined the importance of preoperative depression and anxiety for mortality after cardiac surgery $[2,15,16]$. Although anxiety and depression are highly co-morbid and tend to share risk factors, anxiety is a discrete emotional experience. Anxiety has been characterized as a future-oriented, negative affective state with a component of fear, resulting from the perception of threat and the individual's perceived inability to predict, control, or obtain the desired results in upcoming situations. Symptoms of anxiety may be adversely associated with a high risk of ischemic heart disease [17], and anxiety has been associated with an increased risk of myocardial infarction and fatal ischemic heart disease after CABG [16].

Depression is a prevalent comorbidity in patients with coronary artery disease. The prevalence ranges from 14$47 \%$ with higher rates seen most often in patients with unstable angina or those awaiting CABG surgery [2]. Depression on the day before surgery and depression that persists months after surgery were associated with a twoto threefold increased risk of mortality [18]. According to a recent study about women at high risk for cardiovascular disease not only the presence of depression but also the severity of depression influenced the outcome jointly with or independent of known risk factors [19]. Further research is needed to find the factors responsible for 
Table 2 Adjusted Cox model for medical and psychosocial factors-perioperative and postdischarge model

\begin{tabular}{|c|c|c|c|c|c|c|}
\hline \multirow{3}{*}{ 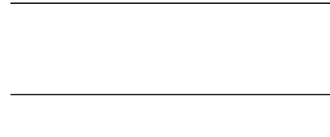 } & \multirow[t]{2}{*}{ B } & \multirow{2}{*}{$\frac{\text { AHR }}{(95 \% \mathrm{Cl})}$} & \multirow[t]{2}{*}{ P value } & \multirow[t]{2}{*}{ B } & \multirow{2}{*}{$\frac{\mathrm{AHR}}{(95 \% \mathrm{Cl})}$} & \multirow[t]{2}{*}{$P$ value } \\
\hline & & & & & & \\
\hline & \multicolumn{3}{|c|}{ Perioperative model } & \multicolumn{2}{|c|}{ Postdischarge model } & \\
\hline EUROSCORE & 0.222 & 1.25 & 0.001 & 0.264 & 1.30 & 0.009 \\
\hline (Additive, points) & & $(1.10-1.41)$ & & & $(1.07-1.58)$ & \\
\hline \multirow[t]{2}{*}{ Preoperative STAI-T (points) } & 0.054 & 1.06 & 0.001 & 0.055 & 1.06 & 0.002 \\
\hline & & $(1.02-1.09)$ & & & $(1.02-1.09)$ & \\
\hline \multirow[t]{2}{*}{ School years } & -0.181 & 0.83 & 0.008 & -0.156 & 0.86 & 0.038 \\
\hline & & $(0.73-0.95)$ & & & $(0.74-0.98)$ & \\
\hline \multirow[t]{2}{*}{ MACCE } & 1.946 & 6.99 & 0.001 & 1.980 & 7.24 & $<0.001$ \\
\hline & & $(2.99-16.9)$ & & & $(2.65-19.7)$ & \\
\hline
\end{tabular}

In the Cox regression model, perioperative variables $p<0.20$ in the univariate analysis were considered. The first model is the perioperative model (second to fourth columns) and the second one is the postdischarge model (fifth to seventh columns). The c-index of the perioperative model was 0.697 before the bootstrapping method and 0.685 thereafter. The c-index of the postdischarge model was 0.691 before the bootstrapping method and 0.681 thereafter. B: regression coefficient, AHR: adjusted hazard ratio, STAI-T: trait anxiety subscale in the Spielberger State-Trait Anxiety Inventory, MACCE: major adverse cardiac and cerebral event.

constant high STAI-T and BDI scores. On the other hand, survivors were more frequently treated than those who died during the follow-up.

In a parallel analysis of preoperative anxiety and depression, only anxiety was significantly associated with increased mortality after adjusting for known mortality risk factors [20]. We have used the additive EUROSCORE for risk estimation for cardiac surgery [7]. The addition of anxiety and education to the risk model might help to further refine the risk factors associated with increased mortality. We found that preoperative STAI-T scores were associated with increased 7-year mortality, and these results highlight the importance of preoperative screening for anxiety in routine clinical practice. In a similar study, patients who had major depression in the hospital just before discharge were more than twice likely to die or be readmitted for cardiac causes in the 12 months after discharge from the hospital than those without this disorder. They also found that major depressive disorder increased the frequency of cardiac events independent of the usual risk factors [15].

Table 3 Interactive Cox regression model for medical factors, anxiety and depression

\begin{tabular}{lccccc}
\hline & B & AHR & \multicolumn{2}{c}{$(\mathbf{9 5 , 0} \%$ C.I. $)$} & P value \\
\hline Euroscore & 0.166 & 1.18 & $(1.05$ & $1.33)$ & 0.007 \\
School years & -0.191 & 0.83 & $(0.72$ & $0.95)$ & 0.008 \\
MACCE & 2.057 & 7.82 & $(3.02$ & 20.27 & $<0.001$ \\
Anxiety & 1.401 & 4.06 & $(1.16$ & $14.20)$ & 0.028 \\
Depression & -11.28 & 0.82 & $(0.42$ & $1.63)$ & 0.98 \\
Anxiety + Depression & 1.59 & 4.93 & $(1.45$ & $16.68)$ & 0.01 \\
\hline
\end{tabular}

In the Cox regression model, perioperative variables $\mathrm{p}<0.20$ in the univariate analysis were considered. The c-index of the model was 0.697 before the bootstrapping method and 0.685 thereafter. B: regression coefficient, AHR: adjusted hazard ratio, MACCE: major adverse cardiac and cerebral event.
These findings suggest that a surgically successful cardiac operation does not always correlate with the improvement of individual life expectancies after surgery [2] and does not decrease level of depressive symptoms [21].

The overlap between anxiety and depression has long been discussed. Most recent research on the pathophysiological links between negative emotions and ischemic heart disease has revealed that depression and anxiety have several similar effects on coronary events, including increased catecholamine levels, indicators of autonomic dysfunction (increased heart rate, decreased heart rate variability, and decreased baroreceptor sensitivity), increased platelet activity, and subacute chronic inflammation [22]. Low education and income are important determinants of all-cause mortality and cardiovascular mortality [23] among patients with myocardial infarction. Low income and education are related to a higher risk profile and poorer treatment [24]. In accordance, in our study, a higher level of education was associated with a longer survival time. Patients with a high level of education are likely to have a higher income and therefore can afford the more expensive "healthy" diet and sport activities [23].

The limitation of our study is the small sample size and thus the lower statistical power. Nevertheless, the applied statistical method strengthened the results of this study. However, it was a single center study; hence, the results may not be generalizable to similar patient populations. Furthermore, we have excluded patients who could not fill out our questionnaires and those undergoing emergent surgery or a concomitant procedure, suggesting that our results may not necessarily generalize to higher risk patients. Smoking history, actual blood pressure and medication after discharge were not recorded during the follow-up period. Additionally, 
we cannot exclude the possibility that the data for the non-responders could have changed the results. The strengths of this study are that in addition to anxiety, education has also been evaluated. Also, this study has a long-term follow up, and the data were collected prospectively. The model created and validated in this study can have an important clinical impact, as it provides a preoperative estimate of an individual patient's risk of death. We have enrolled patients undergoing CABG and/or valve surgery, which can also influence our results, although a previous report did not find significant in-hospital differences in mortality and morbidity [25].

\section{Conclusion}

Our results indicate the long term impact of preoperative anxiety, and lower education for mortality after cardiac surgery. However, patients with cardiovascular disease and treated depression had modest improvement in depressive symptoms but no improvement in cardiac outcomes. Therefore, further research is needed about mechanisms by which anxiety, education, or other psychosocial factors may be related to objective health endpoints [26].

\section{Abbreviations}

STAI-S, State anxiety subscale in the Spielberger state-trait anxiety inventory; STAI-T, Trait anxiety subscale in the Spielberger state-trait anxiety inventory; $\mathrm{BDI}$, Beck depression inventory; Cl, Confidence interval; AHR, Adjusted hazard ratio; $C A B G$, Coronary artery bypass graft; $C B P$, Cardiopulmonary bypass; MACCE, Major adverse cardiac and cerebral event; CHF, Congestive heart failure; ICU, Intensive care unit.

\section{Competing interests}

The authors declare that they have no competing interests.

\section{Authors' contributions}

ASZ, PB and MDK designed the study. ASZ, ZCS, AH and EL collected the clinical data. ASZ, ZCS, TSZT analysed and interpreted the data. ASZ and ZCS drafted the manuscript. ASZ, JG, TSZT and MDK made critical revision of the manuscript for important intellectual content. ASZ and ZCS performed the statistical analysis. JB performed the operation. All authors read and approved the final manuscript.

\section{Acknowledgment}

This manuscript was supported, in part, by the administrative staff of the Department of Anesthesia and Intensive Care, Gottsegen György Hungarian Institute of Cardiology.

\section{Author details \\ ${ }^{1}$ Department of Anesthesiology and Intensive Care, Semmelweis University,

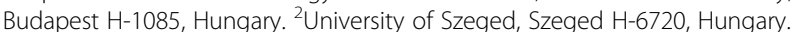 ${ }^{3}$ Institute of Behavioral Sciences, Semmelweis University, Budapest H-1085, Hungary. ${ }^{4}$ Department of Cardiac Surgery of Gottsegen György Hungarian Institute of Cardiology, Budapest $\mathrm{H}-1096$, Hungary. ${ }^{5}$ Department of Anesthesia and Intensive Care, Gottsegen György Hungarian Institute of Cardiology, Haller u. 29, Budapest H-1096, Hungary.}

Received: 8 February 2012 Accepted: 7 September 2012 Published: 14 September 2012

\section{References}

1. Hemingway $H$, Marmot M: Evidence based cardiology: psychosocial factors in the aetiology and prognosis of coronary heart disease.
Systematic review of prospective cohort studies. BMJ 1999, 318(7196):1460-1467.

2. Blumenthal JA, Lett HS, Babyak MA, White W, Smith PK, Mark DB, Jones R, Mathew JP, Newman MF, NORG Investigators: Depression as a risk factor for mortality after coronary artery bypass surgery. Lancet 2003 , 362(9384):604-609.

3. Cohn WE: Advances in surgical treatment of acute and chronic coronary artery disease. Tex Heart Inst J 2010, 37(Suppl 3):328-330.

4. Székely A, Balog P, Benkö E, Breuer T, Székely J, Kertai MD, Horkay F, Kopp MS, Thayer JF: Anxiety predicts mortality and morbidity after coronary artery and valve surgery-a 4-year follow-up study. Psychosom Med 2007, 69:625-631.

5. Brummett BH, Barefoot JC, Siegler IC, Clapp-Channing NE, Lytle BL, Bosworth HB, Williams RB Jr, Mark DB: Characteristics of Socially Isolated Patients With Coronary Artery Disease Who Are at Elevated Risk for Mortality. Psychosom Med 2001, 63:267-272.

6. Rosengren A, Hawken S, Ounpuu S, Sliwa K, Zubaid M, Almahmeed WA, Blackett KN, Sitthi-amorn C, Sato H, Yusuf S, INTERHEART investigators: Association of psychosocial risk factors with risk of acute myocardial infarction in 11119 cases and 13648 controls from 52 countries (the INTERHEART study): case-control study. Lancet 2004, 364:953-962.

7. Roques F, Nashef SA, Michel P, Gauducheau E, de Vincentiis C, Baudet E, Cortina J, David M, Faichney A, Gabrielle F, Gams E, Harjula A, Jones MT, Pintor PP, Salamon R, Thulin L: Risk factors and outcome in European cardiac surgery: analysis of the EUROSCORE multinational database of 19030 patients. Eur J Cardiothorac Surg 1999, 15:816-822.

8. Ferguson TB Jr, Dziubian SW, Edwards FH: Committee to establish a national database in cardiothoracic surgery. The society of thoracic surgeons. The STS database. Current changes and challenges for the new millennium. Ann Thorac Surg 2000, 69:680-691.

9. Beck AT, Steer RA, Brown GK: Beck Depression Inventory-Second Edition Manual. San Antonio: TX: The Psychological Corporation; 1996.

10. Shen BJ, Wachowiak PS, Brooks LG: Psychosocial factors and assessment in cardiac rehabilitation. Eura Medicophys 2005, 41:75-91.

11. Cronbach $\sqcup$ : Coefficient alpha and the internal structure of tests. Psychometrika 1951, 16(Suppl 3):297-334.

12. Spielberger CD, Gorsuch A, Lushane R, Vagg PR, Jacobs GA: Manual for the State-Trait Anxiety Inventory. Palo Alto, California: Consulting Psychologists Press; 1970.

13. Babyak MA: What you see may not be what you get: A brief, nontechnical introduction to overfitting in regression-type models. Psychosom Med 2004, 66:411-421.

14. Albus C: Psychological and social factors in coronary heart disease. Ann Med 2010, 42(Suppl 7):487-494

15. Connerney I, Shapiro PA, McLaughlin JS, Bagiella E, Sloan RP: Relation between depression after coronary artery bypass surgery and 12-month outcome: a prospective study. Lancet 2001, 358(9295):1766-1771.

16. Rosenbloom Jl, Wellenius GA, Mukamal KJ, Mittleman MA: Self-reported anxiety and the risk of clinical events and atherosclerotic progression among patients with Coronary Artery Bypass Grafts (CABG). Am Heart J 2009, 158(Suppl 5):867-873.

17. Jiang W, Kuchibhatla M, Cuffe MS, Christopher EJ, Alexander JD, Clary GL, Blazing MA, Gaulden LH, Califf RM, Krishnan RR, O'Connor CM: Prognostic value of anxiety and depression in patients with chronic heart failure. Circulation 2004, 110(Suppl 22):3452-3456.

18. Phillips-Bute B, Mathew JP, Blumenthal JA, Morris RW, Podgoreanu MV, Smith M, Stafford-Smith M, Grocott HP, Schwinn DA, Newman MF, Perioperative Genetics and Safety Outcomes Investigative Team: Perioperative Genetics and Safety Outcomes Investigative Team. Relationship of genetic variability and depressive symptoms to adverse events after coronary artery bypass graft surgery. Psychosom Med 2008, 70(9):953-959.

19. Rutledge $T$, Linke SE, Johnson BD, Bittner V, Krantz DS, Cornell CE, Vaccarino V, Pepine CJ, Handberg EM, Eteiba W, Shaw LJ, Parashar S, Eastwood JA, Vido DA, Merz CN: Relationships between cardiovascular disease risk factors and depressive symptoms as predictors of cardiovascular disease events in women. J Womens Health (Larchmt) 2012, 21(2):133-139.

20. Tully PJ, Baker RA, Knight JL: Anxiety and depression as risk factors for mortality after coronary artery bypass surgery. J Psychosom Res 2008, 64:285-290 
21. Kustrzycki W, Rymaszewska J, Malcher K, Szczepanska-Gieracha J, Biecek P: Risk factors of depressive and anxiety symptoms 8 years after coronary artery bypass grafting. Eur J Cardiothorac Surg 2012, 41(2):302-306.

22. Frasure-Smith $\mathrm{N}$, Lespérance $\mathrm{F}$ : Depression and anxiety as predictors of 2-year cardiac events in patients with stable coronary artery disease. Arch Gen Psychiatry 2008, 65(Suppl 1):62-71.

23. Kopp M, Skrabski A, Szántó Z, Siegrist J: Psychosocial determinants of premature cardiovascular mortality differences within Hungary. J Epidemiol Community Health 2006, 60:782-788.

24. Gerber Y, Goldbourt U, Drory Y, Israel Study Group on First Acute Myocardial Infarction: Interaction between income and education in predicting long-term survival after acute myocardial infarction. Eur $J$ Cardiovasc Prev Rehabil 2008, 15:526-532.

25. Jenkins $C D$, Jono RT, Stanton BA: Predicting completeness of symptom relief after major heart surgery. Behav Med 1996, 22(Suppl 2):45-57.

26. Thombs BD, de Jonge P, Coyne JC, Whooley MA, Frasure-Smith N, Mitchell AJ, Zuidersma M, Eze-Nliam C, Lima BB, Smith CG, Soderlund K, Ziegelstein RC: Depression screening and patient outcomes in cardiovascular care: a systematic review. JAMA 2008, 300(18):2161-2171.

doi:10.1186/1749-8090-7-86

Cite this article as: Cserép et al:: The impact of preoperative anxiety and education level on long-term mortality after cardiac surgery. Journal of Cardiothoracic Surgery 2012 7:86.

\section{Submit your next manuscript to BioMed Central and take full advantage of:}

- Convenient online submission

- Thorough peer review

- No space constraints or color figure charges

- Immediate publication on acceptance

- Inclusion in PubMed, CAS, Scopus and Google Scholar

- Research which is freely available for redistribution 